\title{
Consistent administration of cetuximab is associated with favorable outcomes in recurrent/metastatic head and neck squamous cell carcinoma in an endemic carcinogen exposure area: a retrospective observational study
}

\author{
Hui-Ching Wang ${ }^{1,2}$, Pei-Lin Liu ${ }^{3,4}$, Pei-Chuan Lo ${ }^{4}$, Yi-Tzu Chang ${ }^{4}$, Leong-Perng Chan ${ }^{1,5}$, Tsung-Jang Yeh ${ }^{1,2}$, Hui- \\ Hua Hsiao ${ }^{2,6}$, Shih-Feng Cho ${ }^{\text {Corresp. 2,6 }}$ \\ ${ }^{1}$ Graduate Institute of Clinical Medicine, College of Medicine, Kaohsiung Medical University, Kaohsiung, Taiwan \\ 2 Division of Hematology and Oncology, Department of Internal Medicine, Kaohsiung Medical University Hospital, Kaohsiung Medical University, \\ Kaohsiung, Taiwan \\ 3 Faculty of Internal Medicine, Specialist Nursing office, Kaohsiung Medical University Hospital, Kaohsiung Medical University, Kaohsiung, Taiwan \\ 4 Department of Nursing, Kaohsiung Medical University Hospital, Kaohsiung Medical University, Kaohsiung, Taiwan \\ 5 Department of Otolaryngology-Head and Neck Surgery, Kaohsiung Medical University Hospital, Kaohsiung Medical University, Kaohsiung, Taiwan \\ 6 Faculty of Medicine, College of Medicine, Kaohsiung Medical University, Kaohsiung, Taiwan \\ Corresponding Author: Shih-Feng Cho \\ Email address: sfcho@kmu.edu.tw
}

Background. This study aimed to analyze the clinical outcomes associated with patients with recurrent/metastatic head and neck squamous cell carcinoma (RM HNSCC) who received cetuximab-based chemotherapy in a real-world clinical setting. Methods. Clinical data were extracted from RM HNSCC patients diagnosed between 2016 and 2019. Kaplan-Meier survival estimates and Cox proportional hazards model were used for survival analyses. Results. Of 106 RM HNSCC patients (mean age $=55.1$ years), $38.7 \%$ exhibited recurrent disease and $61.3 \%$ had metastatic disease. The majority of patients showed a habit of addictive substance use, including alcohol (67.0\%), betel nuts $(71.7 \%)$, or tobacco $(74.5 \%)$. The primary tumor sites included the oral cavity $(64.1 \%)$, hypopharynx $(<19.8 \%)$, and oropharynx (16.0\%). The median number of cetuximab cycles for the 106 patients was 11 (2-24). The disease control rate (DCR) was $48.1 \%$, and the overall response rate (ORR) was $28.3 \%$. The median progression-free survival (PFS) and overall survival (OS) were 5.0 and 9.23 months, respectively. Patients treated with more than 11 cycles of cetuximab exhibited a longer median PFS and median OS than did patients treated with less than 11 cycles (median PFS: 7.0 vs. 3.0 months, $p<0.001$; OS: 12.43 vs. 4.46 months, $p=0.001$ ). Patients without previous concurrent chemoradiotherapy (CRT) had a better median PFS than did those with previous CRT ( 6.0 vs. 4.0 months, $p=0.046$ ). Multivariable analysis revealed that perineural invasion and fewer cycles of cetuximab (<11 cycles) were independent risk factors associated with disease progression. In 
addition, the reduction in treatment cycles of cetuximab and advanced lymph node metastasis were independent prognostic factors predicting poorer overall survival. Conclusion. Our study provides important real-world data regarding cetuximabcontaining treatment in RM HNSCC. Consistent administration of cetuximab could be associated with more favorable outcomes in RM HNSCC in endemic carcinogen exposure areas. 


\section{Consistent administration of cetuximab is associated with}

\section{2 favorable outcomes in recurrent/metastatic head and neck}

\section{3 squamous cell carcinoma in an endemic carcinogen exposure}

4 area: a retrospective observational study

5

6

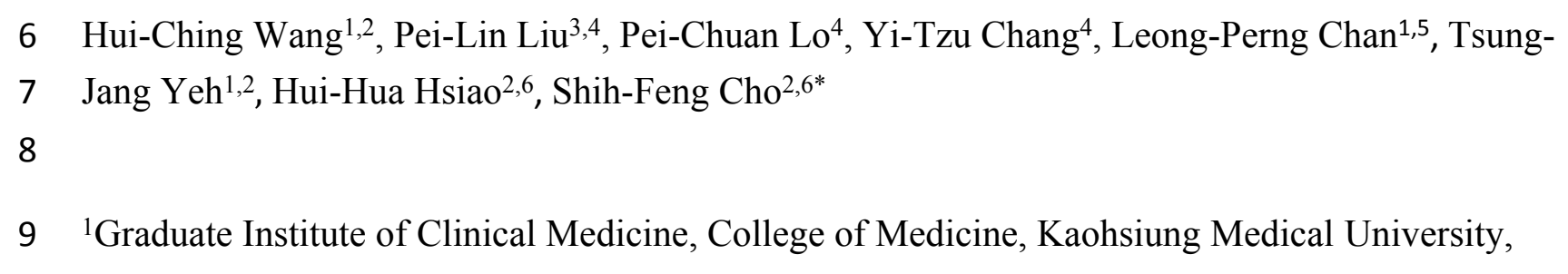

${ }^{2}$ Division of Hematology and Oncology, Department of Internal Medicine, Kaohsiung Medical

University Hospital, Kaohsiung Medical University, Kaohsiung, Taiwan.

${ }^{3}$ Faculty of Internal Medicine, Specialist Nursing Office, Kaohsiung Medical University

Hospital, Kaohsiung Medical University, Kaohsiung, Taiwan

${ }^{4}$ Department of Nursing, Kaohsiung Medical University Hospital, Kaohsiung Medical

University, Kaohsiung, Taiwan

${ }^{5}$ Department of Otolaryngology-Head and Neck Surgery, Kaohsiung Medical University

Hospital, Kaohsiung Medical University, Kaohsiung, Taiwan

${ }^{6}$ Faculty of Medicine, College of Medicine, Kaohsiung Medical University, Kaohsiung, Taiwan 


\section{Corresponding Author:}

22 Shih-Feng Cho

23 No. 100, Tzyou $1^{\text {st }}$ Rd., Sanmin Dist., Kaohsiung City, 80756, Taiwan (R.O.C.)

24 Email address: $\underline{\text { sfcho@ } @ \text { kmu.edu.tw }}$

25 Phone numbers: +886-7-312-1101-6109

26 TAX numbers: +886-7-316-2429

27 
28 Abstract

29 Background. This study aimed to analyze the clinical outcomes associated with patients with 30 recurrent/metastatic head and neck squamous cell carcinoma (RM HNSCC) who received 31 cetuximab-based chemotherapy in a real-world clinical setting. 32

Methods. Clinical data were extracted from RM HNSCC patients diagnosed between 2016 and 2019. Kaplan-Meier survival estimates and Cox proportional hazards model were used for survival analyses.

Results. Of 106 RM HNSCC patients (mean age $=55.1$ years), 38.7\% exhibited recurrent disease and $61.3 \%$ had metastatic disease. The majority of patients showed a habit of addictive substance use, including alcohol $(67.0 \%)$, betel nuts $(71.7 \%)$, or tobacco $(74.5 \%)$. The primary tumor sites included the oral cavity $(64.1 \%)$, hypopharynx $(<19.8 \%)$, and oropharynx $(16.0 \%)$. The median number of cetuximab cycles for the 106 patients was 11 (2-24). The disease control rate (DCR) was $48.1 \%$, and the overall response rate (ORR) was $28.3 \%$. The median progression-free survival (PFS) and overall survival (OS) were 5.0 and 9.23 months, respectively.

Patients treated with more than 11 cycles of cetuximab exhibited a longer median PFS and median OS than did patients treated with less than 11 cycles (median PFS: 7.0 vs. 3.0 months, $p$ $<0.001$; OS: 12.43 vs. 4.46 months, $\mathrm{p}=0.001$ ). Patients without previous concurrent chemoradiotherapy (CRT) had a better median PFS than did those with previous CRT (6.0 vs. 4.0 months, $\mathrm{p}=0.046$ ).

Multivariable analysis revealed that perineural invasion and fewer cycles of cetuximab $(<11$ cycles) were independent risk factors associated with disease progression. In addition, the reduction in treatment cycles of cetuximab and advanced lymph node metastasis were independent prognostic factors predicting poorer overall survival.

Conclusion. Our study provides important real-world data regarding cetuximab-containing treatment in RM HNSCC. Consistent administration of cetuximab could be associated with more favorable outcomes in RM HNSCC in endemic carcinogen exposure areas.

Keywords: recurrent and/or metastatic head and neck cancer, cetuximab, prognosis, survival 


\section{Introduction}

61

62

63

64

65

66

67

68

69

70

71

72

73

74

75

76

77

78

79

80

81

82

83

84

85

86

87

88

89

90

91

92

93

94

95

Head and neck squamous cell carcinoma (HNSCC) is the sixth most common malignancy in the world; recurrent and/or metastatic head and neck squamous cell carcinoma (RM-HNSCC) harbors lethal clinical features and dismal medical outcomes (Parkin et al. 2005). Over 90\% of head and neck cancers are squamous cell carcinomas that develop from the mucosa of the oral cavity, oropharynx, larynx, or hypopharynx (Warnakulasuriya 2009). In Western countries, a subgroup of oropharyngeal SCC is related to human papillomavirus (HPV) infection (Gatta et al. 2015, Gillison et al. 2000). However, oral cavity SCC is the most predominant site of head and neck cancer in Taiwan due to high prevalence of betel nut consumption (Belcher et al. 2014; Chang et al. 2017). Virus-induced HNSCC in Western countries is different from its Taiwanese counterpart in that the mechanism of tumorigenesis of HNSCC in Taiwan is mainly related to carcinogens and addictive substances, including alcohol, betel nuts, and tobacco (Cancer 2012). These carcinogen-related HNSCCs harbor higher Ras oncogene mutations and increased chromosome instability, suggesting that the genetic background and clinical features may be unique to these patients (Chang et al. 1991; Kuo et al. 1994; Riaz et al. 2014).

Epidermal growth factor receptor (EGFR) is usually upregulated with increased levels of its ligand transforming growth factor alpha (TGF- $\alpha$ ) in most HNSCCs, with both proteins contributing to the carcinogenesis of HNSCC (Grandis 2007). Upregulation of EGFR is an independent poor prognostic factor in HNSCCs (Ang et al. 2004; Dassonville et al. 1993). Cetuximab, an IgG1 chimeric monoclonal antibody targeting EGFR, was one of the first-line treatments for RM HNSCC patients with low programmed death ligand 1 (PD-L1) expression (Burtness et al. 2019; Vermorken et al. 2008).The addition of cetuximab to platinum-based chemotherapy with fluorouracil (platinum-fluorouracil) improved the overall response rates, median progression-free survival (PFS), and overall survival (OS) compared with chemotherapy alone. Another combination of cetuximab with chemotherapy agents such as taxane also demonstrated substantial benefits (Adkins et al. 2018; Friesland et al. 2018; Guigay et al. 2019). However, most of these clinical trials were conducted in Western countries with fewer patients with primary oral cavity cancer; data regarding the effect of carcinogens such as betel nuts on outcome are very limited. In addition, the percentage of HPV infection status is quite different between Asian and Western countries, suggesting distinct tumor microenvironments (Wang et al. 2019).

2 In Taiwan, cetuximab combined with systemic chemotherapy has been indicated as first line treatment in patients with RM HNSCC by the National Health Insurance since 2016. After receiving approval for application, the patients can receive cetuximab-containing treatment without copayment. Because of limited financial resources, cetuximab can only be administered 
96 in a total of eighteen cycles if no progression is noted. Unlike clinical trials that provide subjects

97 with maintenance cetuximab, patients in real life cannot afford continuous maintenance with

98 high-cost cetuximab to control their disease. Therefore, modifying the treatment protocol wound

99 be a possible strategy (Hsu \& Lu 2016; Shih et al. 2015). Nevertheless, the impact of

100 modifications such as limiting cetuximab treatment cycle on patient outcome remains unknown.

101 Moreover, real-world data on cetuximab in RM HNSCC patients with high percentages of

102 exposure to various carcinogen remains are also very limited. To answer these questions, we

103 conducted this retrospective and single-arm study to analyze clinical data, hoping to determine

104 the clinical outcomes and prognostic factors in this subset of RM HNSCC patients.

105

106 Materials and methods

107 Patient characteristics

108 Clinicopathological data of patients with HNSCC were confirmed by pathological

109 examination of specimens from biopsy or surgery, and the positive samples were collected and

110 analyzed. A total of 106 cases of RM HNSCC were identified with metastasis or recurrence and

111 were deemed unsuitable for locoregional curative treatment at the Kaohsiung Medical University

112 Hospital. The inclusion criteria included: age at diagnosis 20 years or older; tumor histology of

113 squamous cell carcinoma (grade 1 to grade 3); ICD-9 site code-specific for the oral cavity (OC),

114 hypopharynx (HPC), oropharynx (OPC), and larynx; and treatment with cetuximab from January

1152016 to April 2019. The exclusion criteria included secondary malignancy; tumor histology of

116 carcinoma in situ; and SCC of the nasopharynx or salivary glands.

117

\section{Study design}

119 This was an observational, retrospective, single-center, single-arm study, and the treatment 120 schema is shown in Fig. 1. The collected medical and demographic data included age, gender, 121 alcohol, betel nut usage, tobacco habits, and other clinical parameters obtained from the medical

122 records or interviews with patients. The clinicopathological factors included types and grade of

123 histology, size of tumor, lymph node status, surgical margin, perineural invasion,

124 lymphovascular invasion, and extranodal extension. We defined CRT (chemoradiotherapy)-

125 refractory patients as patients with disease progression during CRT or within three months of the

126 end of CRT. The primary endpoints were median OS and PFS. Specifically, the median OS and

127 PFS (defined as the time from registration to objective disease progression or death from any

128 cause) were determined after the addition of cetuximab to chemotherapy. Other endpoints

129 included the assessment of treatment response and disease control. This study was approved by

130 the Institutional Review Board and Ethics Committee of Kaohsiung Medical University Hospital

131 (KMUHIRB-E(II)-20190357). The data were analyzed anonymously, and therefore, no 
132 additional informed consent was required. All methods were performed in accordance with 133 approved guidelines and regulations.

134

135

136

137

138

139

140

141

142

143

144

145

146

147

148

149

150

151

152

153

154

155

156

157

158

159

160

161

162

163

164

165

166

167

\section{Treatment}

All patients received cetuximab $\left(250 \mathrm{mg} / \mathrm{m}^{2}\right)$ weekly with a loading dose of $400 \mathrm{mg} / \mathrm{m}^{2}$ until disease progression was noted. The regimen of chemotherapy included PF 75/1000 (cisplatin at $75 \mathrm{mg} / \mathrm{m}^{2}$ or carboplatin at $\mathrm{AUC}=5$ every 3 weeks plus fluorouracil at 1,000 $\mathrm{mg} / \mathrm{m}^{2} / \mathrm{d}$ for 4 days every 3 weeks), PF $60 / 800$ (cisplatin at $60 \mathrm{mg} / \mathrm{m}^{2}$ or carboplatin at AUC5 every 3 weeks plus fluorouracil at $800 \mathrm{mg} / \mathrm{m}^{2} / \mathrm{d}$ for 4 days every 3 weeks), taxane-based chemotherapy (docetaxel and cisplatin $75 \mathrm{mg} / \mathrm{m}^{2}$ both at day 1 and every 3 weeks for four courses of paclitaxel $80 \mathrm{mg} / \mathrm{m}^{2}$ weekly), and MTX (methotrexate $40 \mathrm{mg} / \mathrm{m}^{2}$ weekly). The patients could receive chemotherapy or concurrent chemoradiotherapy with weekly cisplatin administration previously before recruitment.

\section{Treatment Response and Safety Assessment}

All patients were followed regularly as outpatients at the medical oncology and department (OPD) of otorhinolaryngology. During the cetuximab treatment period, the patients visited the OPD of medical oncology weekly and that of otorhinolaryngology monthly. The evaluation of disease status included tumor site inspection, laboratory text, and imaging studies. Treatment response was assessed and determined using computed tomography (CT) or magnetic resonance imaging (MRI) at baseline (before cetuximab) and at 3-month intervals after treatment was started. Imaging within 4 weeks before cetuximab was acceptable, and imaging could be performed whenever clinical physicians suspected disease progression. RECIST version 1.1 was used to determine disease progression and tumor response.

The treatment response of patients was classified into four categories: complete response (CR, disappearance of all target lesions), partial response (PR, decrease in target lesion diameter sum $>30 \%$ ), progression disease (PD, increase in target lesion diameter sum $>20 \%$ ), and stable disease (SD, does not meet other criteria). The calculation of overall response rate (ORR), including patients classified as having complete and partial responses, was based on the best objective response achieved during cetuximab treatment. The calculation of disease control rate (DCR) included patients classified as having complete response, partial response, and stable disease. After disease progression, further treatments and survival status were documented every 3 months. Regarding safety assessment, treatment-related adverse events were monitored weekly throughout the study and were evaluated using Common Terminology Criteria for Adverse Events version 4.0. 
168

169

170

171

172

173

174

175

176

177

178

179

180

181

182

183

184

185

186

187

188

189

190

191

192

193

194

195

196

197

198

199

200

201

202

203

\section{Statistical Analysis}

The primary goal of the study was to analyze the outcome of cetuximab-based chemotherapy in recurrent or metastatic settings, including a comparison between median PFS and OS among patients receiving various cycles of cetuximab and regimens of chemotherapy. The location of primary sites (OC, OPC, or HPC), histological grade (Grades 1, 2, 3), tumor size and status (T1, T2, T3, T4), lymph node status (N0, N1, N2, N3), stage at initial diagnosis (I, II, III, or IV), surgery status (with or without previous surgery), CRT (with or without previous CRT), and chemotherapy before cetuximab therapy (with or without prior chemotherapy) were all included for analysis. Between-group comparisons were analyzed using Fisher's exact test and Pearson's chi-square test for various categorical variables. We calculated median PFS and OS using Kaplan-Meier analysis, and we analyzed differences between the curves using the logrank test. We defined the median PFS as the time between the start of disease progression and treatment, including disease progression or death. Patients alive and without disease progression by the final follow-up visit were considered potential right censoring subjects, and the follow-up interval was truncated at the end of study. Univariate and multivariable analyses using the Cox proportional hazard model were preformed to analyze prognostic factors associated with cetuximab treatment. The factors for this analysis included age at initial diagnosis, location of primary sites, histological grade, pathological features (margin, lymphovascular invasion, perineural invasion, and extranodal extension), tumor size, lymph node status, stage at initial diagnosis, previous treatment before cetuximab (surgery, chemotherapy, or CRT), combined regimen and dosage of chemotherapy. All $p$-values were considered significant if $p<0.05$ and were two-sided. Statistical analyses were performed using STATA version 11 (STATA Corp., TX, USA).

\section{Results}

\section{Baseline characteristics of patients}

Clinical data from 106 patients (99 males and 7 females) with a median age of 55.1 years were collected. Among these patients, 65 patients (61.3\%) had metastatic disease and 41 patients $(38.4 \%)$ had recurrent disease with initiation of cetuximab. Almost all patients had addictions to alcohol or betel nuts or history of smoking, including 61 patients $(57.5 \%)$ with exposure to all three carcinogens. Only 5 patients $(4.7 \%)$ had no previous exposure to these risk factors. Regarding the tumor site, most of the primary sites had origins in the oral cavity $(64.1 \%)$, followed by the hypopharynx (19.8\%), and oropharynx (16.0\%). The majority of patients had advanced disease, including T3-4, N2-3, or clinical stage 4. The details of basic information of the study population are listed in Table 1. 
204

205

206

207

208

209

210

211

212

213

214

215

216

217

218

219

220

221

222

223

224

225

226

227

228

229

230

231

232

233

234

235

236

237

238

239

\section{Treatment modality}

With respect to prior treatment before cetuximab treatment, most patients had undergone various HNSCC treatments, including surgery (78.3\%), chemotherapy $(81.1 \%)$ and CRT (80.2\%). In addition, there were 34 CRT-refractory patients who suffered from disease progression during CRT or within three months of the end of CRT.

The major reason for cetuximab treatment was recurrent disease with metastatic tumors. The median number of cycles of cetuximab was 11 (2-24), with 60 patients receiving $\geq 11$ cycles of cetuximab, and 46 patients receiving $<11$ cycles of cetuximab. Among these patients, 76 patients received chemotherapy with the EXTREME regimen (cisplatin and fluorouracil) and 17 patients received taxane-based chemotherapy. The median number of cetuximab administration cycles in these 76 patients with a PF regimen was 11 (range: 2-24) while the median number of cetuximab cycles in 17 patients using taxane-based regimen was 12 (range: 4-23). There was no significant difference in the number of cetuximab cycles between the two groups $(\mathrm{p}=0.427)$. The details of the treatment modalities are shown in Table 2. The demographic data of various cetuximab cycles $(\geq 11$ and $<11)$ are shown in Supplementary Tables S1 and S2. Interestingly, there was no difference in terms of previous treatments, including surgery, chemotherapy, and CRT, between patients who received $<11$ cycles of cetuximab and those who received $\geq 11$ cycles of cetuximab.

\section{Treatment outcomes}

After cetuximab treatment, clinical responses were observed in 30 patients including 1 complete response and 29 partial responses, with ORR of $28.3 \%$. When the patients with stable disease $(n=21,19.8 \%)$ were included in the analysis, the disease control rate was $48.1 \%$. The median PFS and OS were 5 months and 9.23 months, respectively. As of the cut-off date, only one patient did not progress, and 38 patients survived. The median PFS was 5 months (95\% CI 3.0-6.0 months) and the median OS was 9.23 months (95\% CI 7.03-13.84 months). The treatment responses according to various stages are shown in Supplementary Table S3.

The median PFS in various subgroups stratified by treatment modalities is shown in Fig. 2 . Notably, the patients who received more cetuximab treatment ( $\geq 11$ cycles) had a better median PFS than did patients who received less cetuximab ( 7 months vs 3 months, $p<0.001$ ). The median PFS was longer in patients without prior CRT (6 months vs 4 months, $p=0.046$ ). Other factors including chemotherapy regimen (PF or taxane-based), chemotherapy dose (PF dose), or CRT refraction status did not lead to significant effect on PFS. In regard to analysis of OS, the patients who received more cetuximab treatment ( $\geq 11$ cycles) had a better median OS than those who received less cetuximab (12.43 months vs 4.46 months, $\mathrm{p}<0.001)$. Other factors, including chemotherapy regimen and dose, did not lead to significant effects on PFS. The OS curves are 
240 shown in Fig. 3.

241 Next, we applied a landmark method for further validation. Because responses could be

242 observed within the first 3 months following cetuximab exposure, a 3-month landmark was used.

243 After excluding patients who progressed or died within the three months, the patients with more

244 cycles of cetuximab ( $\geq 11$ cycles) still showed better median PFS ( 8 months vs 2 months, $\mathrm{p}=$

$2450.057)$ and OS (13.9 months vs 5.07 months, $p=0.0002)$ than the patients treated with fewer

246 cycles of cetuximab.

247 To clarify the effects of CRT-refraction on survival, we evaluated median PFS and OS in 248 patients with or without CRT-refraction. In the non-CRT-refractory cohort $(\mathrm{n}=72)$, the median

249 PFS and OS were 5.00 months $(95 \% \mathrm{CI}=3.00-7.00)$ and 10.43 months $(95 \% \mathrm{CI}=7.03-14.64)$,

250 respectively. The 3-year OS was $28.72 \%(95 \% \mathrm{CI}=17.25-41.24)$. On further evaluation of these

25172 subjects, 27 patients with $<11$ cetuximab cycles obtained a 3-year PFS rate of 3.70\% $(95 \%$

$252 \mathrm{CI}=0.27-15.90)$, and a 3 -year OS rate of 2.22\% $(95 \% \mathrm{CI}=0.18-10.15)$. Additionally, 45

253 patients with $\geq 11$ cetuximab cycles obtained a 3 -year PFS rate of $11.57 \%(95 \% \mathrm{CI}=1.04-$

254 36.08), and a 3-year OS rate of 37.07\% (95\% CI = 21.60-52.59). The patients treated with more

255 cetuximab cycles also showed a better median PFS and OS then did the patients treated with

256 fewer cetuximab cycles, shown in Fig. 4.

257 In the CRT-refractory patients, the median PFS and OS were 3.00 months $(95 \% \mathrm{CI}=3.00-$

$2586.00)$ and 7.8 months, respectively. The 3 -year OS rate was $25.30 \%(95 \% \mathrm{CI}=10.32-43.53)$. Six

259 CRT-refractory patients who used taxane-based regimens obtained a median PFS and OS of 3.00

260 months $(95 \% \mathrm{CI}=2.00-8.00)$ and 5.62 months $(95 \% \mathrm{CI}=2.03-\mathrm{NA})$, respectively. The 3-year

261 OS was $16.67 \%(95 \% \mathrm{CI}=0.77-51.68)$.

262

263

\section{Risk factor investigation for disease progression}

264

265

Risks of disease progression were analyzed using univariate regression consisting of

266 parameters as age, alcohol, betel nuts, tobacco consumption, tumor site, margin positivity,

267 histologic features (including lymphovascular invasion, perineural invasion, and extranodal

268 extension), tumor size, lymph node status, stage, previous treatment modality (including surgery,

269 chemotherapy, and CRT), treatment status, cetuximab cycles, dose, and regimens of

270 chemotherapy. In addition, a subsequent multivariable regression analysis was performed to evaluate the significant progression factors in univariate analysis.

271

As shown in Table 3, positive perineural invasion was the independent factor related with

272 shorter median PFS. N3 disease showed a trend toward poorer PFS ( $p=0.055$, univariate

273 analysis). After adjustment for other different variables in the multivariable analysis, this

274 difference became significant $(\mathrm{HR}=2.57 ; p=0.043)$. Significantly, treatment with more

275 cetuximab cycles ( $\geq 11$ cycles) was a favorable factor associated with better median PFS (HR $=$ 
276 277

278

279

280

281

282

283

284

285

286

287

288

289

290

291

292

293

294

295

296

297

298

299

300

301

302

303

304

305

306

307

308

309

310

311

$0.19 ; p<0.001$, and $\mathrm{HR}=0.18 ; p<0.001$ in univariate and multivariable analysis, respectively).

\section{Determining the risk factor for poorer overall survival}

Similar clinicopathological factors were analyzed for overall survival. N2 disease had a significantly negative impact on $\mathrm{OS}(\mathrm{HR}=2.09 ; p=0.022$ and $\mathrm{HR}=4.79 ; p=0.006$ in univariate and multivariable analyses, respectively). Treatment with more cetuximab cycles showed a significant, positive effect on $\mathrm{OS}(\mathrm{HR}=0.46 ; p=0.002$ and $\mathrm{HR}=0.48 ; p=0.010$ in both univariate and multivariable analyses, respectively). Other factors with trends toward shorter OS included N3 disease $(p=0.170)$. After adjustment for other variables, this difference became significant in the multivariable analysis $(\mathrm{HR}=7.34 ; p=0.005)$. These results are shown in Table 4.

Although endemic habits showed no significant impact on PFS and OS, multiple endemic habits might increase risk in PFS and OS compared to single or double endemic habits. The impact of multiple endemic habits on PFS and OS are summarized in Supplementary Table S4.

\section{Safety and tolerability}

All grades and the worst grade 3 and grade 4 treatment-related adverse events (AEs) in patients receiving cetuximab therapy are listed in Table 5. Among the patients treated with the platinum/5FU and cetuximab regimen, the most common AEs were skin rash $(2.6 \%)$, anemia (2.6\%), neutropenia (1.3\%), vomiting $(1.3 \%)$ and fever $(1.3 \%)$. Among patients treated with taxane-based regimens, only one patient suffered from grade 3 fever (5.9\%). There were no grade 3 or grade 4 AEs in other groups. In general, skin rash was the most frequent cetuximabrelated AE; however, most of patients tolerated it. There was no interstitial lung disease observed in our patients.

\section{Discussion}

The treatment options for HNSCC are sophisticated and require multidisciplinary groups to tailor personalized treatment. Since 2008, the addition of cetuximab to chemotherapy has become the first-line treatment of RM HNSCC regarding advancements in response and survival (Vermorken et al. 2008). However, HNSCC is a heterogenous disease and considerable effects of carcinogens have been reported, especially in the Asian population (Network 2015).

Accessibility to expensive drugs and restrictions on reimbursement policies also have impacts on the responses and outcomes of treatment in many countries, including Taiwan (Davidoff et al. 2018; Hsu et al. 2019; Morgan \& Kennedy 2010). This retrospective study highlights the important role of cetuximab cycles in RM HNSCC, especially in an endemic carcinogen exposure area such as Taiwan. 
312

313

314

315

316

317

318

319

320

321

322

323

324

325

326

327

328

329

330

331

332

333

334

335

336

337

338

339

340

341

342

343

344

345

346

347

In this study, 106 patients treated with cetuximab-based regimens were assessed; most patients had the habit of using an addictive substance and over half the patients had concurrent exposure to all three addictive substances. However, our outcomes were not inferior when indirectly compared to those of other clinical trials, including the EXTREME regimen conducted by European cancer institutes (De Mello et al. 2014) and the EXTREME trial (Vermorken et al. 2008). The possible reasons may relate to regular and frequent follow-up, laboratory, and imaging studies to detect disease progression and guide subsequent treatment plan when progression was noted. Compared to the aforementioned Asian trial, including Japanese (Tahara et al. 2016) and Chinese trials (Guo et al. 2014), the ORR of our study was slightly lower, which may be related to usage of cetuximab maintenance, different regimens of chemotherapy, and a patient population with distinct endemic carcinogen exposures. The patients in the Japanese trial received cetuximab maintenance and chemotherapy with carboplatin and paclitaxel. However, there was nearly no effect of betel nuts in the Japanese population. The effects of carcinogen were also not mentioned in the Chinese and Korean population. The results of these studies are summarized in Table 6 (Adkins et al. 2018; Bossi et al. 2017; De Mello et al. 2014; Friesland et al. 2018; Guigay et al. 2016; Guigay et al. 2012; Guigay et al. 2019; Guo et al. 2014; Tahara et al. 2016; Vermorken et al. 2008).

Importantly, the median PFS and OS of our study are compatible with those of another retrospective study (De Mello et al. 2014). Our real-world results were also comparable with those of other clinical trials. As we mentioned, these may be related to every diagnosed patient receiving frequent physical and imaging examinations, receiving care from a multidisciplinary team (including nurse case management, integrating expertise of medical oncologist, surgeon, radiologists, case managers, nurses, nutritionists, and pharmacists), and meeting periodically to discuss treatment direction, evaluating therapeutic effects, and providing further recommendations. As noted in breast cancer care, earlier detection from more aggressive monitoring could lead to improved treatment strategies and possibly improved survival (Graham et al. 2014).

Although our study was conducted retrospectively in a single medical center, our study reflects the observation of the real-world setting in an endemic carcinogen exposure area. However, our study still had limitations in terms of relatively smaller sample size and inevitable time bias. To address the immortal time bias and reverse causality, we applied landmark analysis, which suggested more cycles of cetuximab may bring survival benefit to HNSCC patients. The heterogeneous study population is also an issue. Unlike the EXTREME or TPEX studies that excluded CRT-refractory patients, we included CRT-refractory patients.

Furthermore, patients who received nonplatinum chemotherapy regimens, including taxane and MTX, were also included. Heterogeneity of the study population may confound the analysis. 
348 However, our findings revealed real-world conditions in term of financial burden of novel 349 treatment, which lead to absence of cetuximab maintenance. In addition, our study included a 350 Taiwanese population with high incidence of oral cavity cancer that may be related to strong 351 carcinogen exposure, including alcohol, betel nuts, and tobacco. Previous studies had revealed

352 lower expression of tumor suppressor gene $\mathrm{p} 53$ alterations, higher percentage of MDM2 protein 353 expression, as well as higher rate of Ras oncogene mutation after long-term exposure to betel 354 nuts (Huang et al. 2001; Kuo et al. 1994; Kuo et al. 1999). The upregulation of EGFR has been 355 confirmed in betel-nut-associated cancer of the oral cavity associated with poor prognosis (Sheu 356 et al. 2009). Three amplicons (KRAS, MAPK1, and CCND1) have been observed in cancer of 357 oral cavity from Taiwanese patients, and therefore, all could possibly contribute to activation of 358 EGFR signaling (Sheu et al. 2009). EGFR protein upregulation, excluding the effect of $E G F R$ 359 gene copy number on protein overexpression, was related to poor differentiation of tumor cells 360 361 362 363

\section{Conclusions} and lymph node metastasis, especially extranodal extension (Huang et al. 2017). Taken together, cetuximab targeting EGFR on HNSCC cells induces potent antibody-dependent cell-mediated cytotoxicity that further augments anti-tumor effect when combined with chemotherapy (Specenier \& Vermorken 2013).

The restrictions in targeted therapy-related reimbursement policies defer patients' benefits related to RM HNSCC. The limitation of a total 18 cycles of cetuximab without maintenance has been in place since 2016 in Taiwan. In other countries, cetuximab maintenance plays an important role in improving survival and outcomes with tolerable adverse events (Wakasugi et al. 2015). The median duration of maintenance was 11 weeks in the EXTREME trial, 16 weeks in a real-world study in France, and 17 weeks in a real-world study in Portugal. Broadening the duration of the eligible patient population to targeted therapies may be an effective way to improve clinical outcomes of treatments.

Consistent administration of cetuximab provides potential clinical benefits in HNSCC patients in endemic carcinogen exposure areas in an Asian population; therefore, longer cetuximab maintenance therapy is urgently warranted in these patients with poor prognoses.

\section{Acknowledgments}

We acknowledge support from the following grants: KMUH107-7M12, KMUH108-8R23, 381 KMUH108-8M12, and KMHK-DK109004 from the Kaohsiung Medical University Hospital.

\section{References}

Adkins D, Ley J, Atiq O, Rigden C, Trinkaus K, Wildes T, and Oppelt P. 2018. Multicenter phase 2 trial of 
384

385

386

387

388

389

390

391

392

393

394

395

396

397

398

399

400

401

402

403

404

405

406

407

408

409

410

411

412

413

414

415

416

417

418

419 cis/carboplatin, nAb-paclitaxel, and CeTUXimab (CACTUX) as first-line therapy for recurrent/metastatic head and neck squamous cell carcinoma. International Journal of Radiation Oncology• Biology• Physics 100:1311-1312.

Ang KK, Andratschke NH, and Milas L. 2004. Epidermal growth factor receptor and response of head-and-neck carcinoma to therapy. International Journal of Radiation Oncology* Biology* Physics 58:959-965.

Belcher R, Hayes K, Fedewa S, and Chen AY. 2014. Current treatment of head and neck squamous cell cancer. Journal of surgical oncology 110:551-574.

Bossi P, Miceli R, Locati L, Ferrari D, Vecchio S, Moretti G, Denaro N, Caponigro F, Airoldi M, and Moro C. 2017. A randomized, phase 2 study of cetuximab plus cisplatin with or without paclitaxel for the first-line treatment of patients with recurrent and/or metastatic squamous cell carcinoma of the head and neck. Annals of Oncology 28:2820-2826.

Burtness B, Harrington KJ, Greil R, Soulières D, Tahara M, de Castro G Jr, Psyrri A, Basté N, Neupane P, Bratland Å, Fuereder T, Hughes BGM, Mesía R, Ngamphaiboon N, Rordorf T, Wan Ishak WZ, Hong RL, González Mendoza R, Roy A, Zhang Y, Gumuscu B, Cheng JD, Jin F, Rischin D; KEYNOTE-048 Investigators. 2019. Pembrolizumab alone or with chemotherapy versus cetuximab with chemotherapy for recurrent or metastatic squamous cell carcinoma of the head and neck (KEYNOTE-048): a randomised, open-label, phase 3 study. Lancet 394:1915-1928.

Cancer IAfRo. 2012. A review of human carcinogens: personal habits and indoor combustions: World Health Organization.

Chang PMH, Lu HJ, Wang LW, Tai SK, Chen MH, Chu PY, and Yang MH. 2017. Effectiveness of incorporating cetuximab into docetaxel/cisplatin/fluorouracil induction chemotherapy and chemoradiotherapy for inoperable squamous cell carcinoma of the oral cavity: A phase II study. Head \& neck 39:1333-1342.

Chang SE, Bhatia P, Johnson NW, Morgan PR, McCormick F, Young B, and Hiorns L. 1991. Ras mutations in United Kingdom examples of oral malignancies are infrequent. Int J Cancer 48:409-412.

Dassonville O, Formento J, Francoual M, Ramaioli A, Santini J, Schneider M, Demard F, and Milano G. 1993. Expression of epidermal growth factor receptor and survival in upper aerodigestive tract cancer. Journal of Clinical Oncology 11:1873-1878.

Davidoff AJ, Guy Jr GP, Hu X, Gonzales F, Han X, Zheng Z, Parsons H, Ekwueme DU, and Jemal A. 2018. Changes in health insurance coverage associated with the affordable care act among adults with and without a cancer history: population-based national estimates. Medical care 56:220.

De Mello RA, Geros S, Alves MP, Moreira F, Avezedo I, and Dinis J. 2014. Cetuximab plus platinum-based chemotherapy in head and neck squamous cell carcinoma: a retrospective study in a single comprehensive European cancer institution. PloS one 9:e86697.

Friesland S, Tsakonas G, Kristensen C, Herlestam Calero Moren M, Haugen H, Soderstrom K, and Specht L. 2018. Randomised phase II study with cetuximab in combination with 5-FU and cisplatin or carboplatin versus cetuximab in combination with paclitaxel and carboplatin for treatment of patients with relapsed or

Peer] reviewing PDF | (2020:01:45342:2:1:NEW 12 Aug 2020) 
420

421

422

423

424

425

426

427

428

429

430

431

432

433

434

435

436

437

438

439

440

441

442

443

444

445

446

447

448

449

450

451

452

453

454

455 metastatic squamous cell carcinoma of the head and neck (CETMET trial). American Society of Clinical Oncology.

Gatta G, Botta L, Sánchez MJ, Anderson LA, Pierannunzio D, Licitra L; EUROCARE Working Group. 2015. Prognoses and improvement for head and neck cancers diagnosed in Europe in early 2000s: The EUROCARE-5 population-based study. European Journal of Cancer 51:2130-2143.

Gillison ML, Koch WM, Capone RB, Spafford M, Westra WH, Wu L, Zahurak ML, Daniel RW, Viglione M, and Symer DE. 2000. Evidence for a causal association between human papillomavirus and a subset of head and neck cancers. J Natl Cancer Inst 92:709-720.

Graham L, Shupe MP, Schneble EJ, Flynt FL, Clemenshaw MN, Kirkpatrick AD, Gallagher C, Nissan A, Henry L, and Stojadinovic A. 2014. Current approaches and challenges in monitoring treatment responses in breast cancer. Journal of Cancer 5:58.

Grandis JR. 2007. Established and emerging concepts in epidermal growth factor receptor biology. International Journal of Radiation Oncology• Biology• Physics 69:S22-S24.

Guigay J, Chamorey E, Céruse P, Mornex F, Degardin M, Alfonsi M, Digue L, Berrier A, Artignan X, and Cals L. 2016. Observational study of the cetuximab relative dose intensity (RDI) in the first-line treatment of recurrent and/or metastatic squamous cell carcinoma of the head and neck (R/M SCCHN): Data on the maintenance and every two weeks use (DIRECT study). Annals of Oncology 27.

Guigay J, Fayette J, Dillies A-F, Sire C, Kerger JN, Tennevet I, Machiels J-PH, Zanetta S, Pointreau Y, and Bozec Le Moal L. 2012. Cetuximab, docetaxel, and cisplatin (TPEx) as first-line treatment in patients with recurrent or metastatic (R/M) squamous cell carcinoma of the head and neck (SCCHN): final results of phase II trial GORTEC 2008-03. American Society of Clinical Oncology.

Guigay J, Fayette J, Mesia R, Lafond C, Saada-Bouzid E, Geoffrois L, Martin L, Cupissol D, Capitain O, and Castanie H. 2019. TPExtreme randomized trial: TPEx versus Extreme regimen in 1st line recurrent/metastatic head and neck squamous cell carcinoma (R/M HNSCC). American Society of Clinical Oncology.

Guo Y, Shi M, Yang A, Feng J, Zhu X, Choi YJ, Hu G, Pan J, Hu C, Luo R, Zhang Y, Zhou L, Cheng Y, Lüpfert C, Cai J, Shi Y. 2015. Platinum-based chemotherapy plus cetuximab first-line for Asian patients with recurrent and/or metastatic squamous cell carcinoma of the head and neck: Results of an open-label, single-arm, multicenter trial. Head Neck 37:1081-1087.

Hsu JC, and Lu CY. 2016. Longitudinal trends in use and costs of targeted therapies for common cancers in Taiwan: a retrospective observational study. BMJ open 6:e011322.

Hsu JC, Wei C-F, and Yang S-C. 2019. Effects of removing reimbursement restrictions on targeted therapy accessibility for non-small cell lung cancer treatment in Taiwan: an interrupted time series study. BMJ open 9:e022293.

Huang JS, Ho TJ, Chiang CP, Kok SH, Kuo YS, and Kuo MY. 2001. MDM2 expression in areca quid chewing-associated oral squamous cell carcinomas in Taiwan. J Oral Pathol Med 30:53-58.

Huang SF, Chien HT, Chuang WY, Lai CH, Cheng SD, Liao CT, and Wang HM. 2017. Epidermal growth factor receptor

Peer) reviewing PDF | (2020:01:45342:2:1:NEW 12 Aug 2020) 
456

457

458

459

460

461

462

463

464

465

466

467

468

469

470

471

472

473

474

475

476

477

478

479

480

481

482

483

484

485

486

487

488

489

490

491

intron-1 CA repeat polymorphism on protein expression and clinical outcome in Taiwanese oral squamous cell carcinoma. Sci Rep 7:4963. 10.1038/s41598-017-04954-5

Kuo MY-P, Jeng J, Chiang C-P, and Hahn L. 1994. Mutations of Ki-ras oncogene codon 12 in betel quid chewing-related human oral squamous cell carcinoma in Taiwan. Journal of oral pathology \& medicine 23:70-74.

Kuo MYP, Huang JS, Hsu HC, Chiang CP, Kok SH, Kuo YS, and Hong CY. 1999. Infrequent p53 mutations in patients with areca quid chewing-associated oral squamous cell carcinomas in Taiwan. Journal of oral pathology \& medicine 28:221-225.

Morgan S, and Kennedy J. 2010. Prescription drug accessibility and affordability in the United States and abroad. Issue brief (Commonwealth Fund) 89:1-12.

Network CGA. 2015. Comprehensive genomic characterization of head and neck squamous cell carcinomas. Nature 517:576.

Parkin DM, Bray F, Ferlay J, and Pisani P. 2005. Global cancer statistics, 2002. CA: a cancer journal for clinicians 55:74-108.

Riaz N, Morris LG, Lee W, and Chan TA. 2014. Unraveling the molecular genetics of head and neck cancer through genome-wide approaches. Genes \& diseases 1:75-86.

Sheu JJ-C, Hua C-H, Wan L, Lin Y-J, Lai M-T, Tseng H-C, Jinawath N, Tsai M-H, Chang N-W, and Lin C-F. 2009. Functional genomic analysis identified epidermal growth factor receptor activation as the most common genetic event in oral squamous cell carcinoma. Cancer Res 69:2568-2576.

Shih Y-CT, Smieliauskas F, Geynisman DM, Kelly RJ, and Smith TJ. 2015. Trends in the cost and use of targeted cancer therapies for the privately insured nonelderly: 2001 to 2011. Journal of Clinical Oncology 33:2190.

Specenier P, and Vermorken JB. 2013. Cetuximab: its unique place in head and neck cancer treatment. Biologics: targets \& therapy 7:77.

Tahara M, Kiyota N, Yokota T, Hasegawa Y, Muro K, Takahashi S, Onoe T, Homma A, Taguchi J, and Suzuki M. 2016. Phase II trial of combination treatment with paclitaxel, carboplatin and cetuximab (PCE) as first-line treatment in patients with recurrent and/or metastatic squamous cell carcinoma of the head and neck (CSPOR-HNO2). American Society of Clinical Oncology.

Vermorken JB, Mesia R, Rivera F, Remenar E, Kawecki A, Rottey S, Erfan J, Zabolotnyy D, Kienzer H-R, and Cupissol D. 2008. Platinum-based chemotherapy plus cetuximab in head and neck cancer. New England Journal of Medicine 359:1116-1127.

Wakasugi T, Enokida T, Nakanome A, Yamazaki T, Okano S, and Tahara M. 2015. 319P The role of cetuximab maintenance after chemotherapy in patients with recurrent/metastatic squamous cell carcinoma of head and neck (R/M SCCHN): A retrospective analysis. Annals of Oncology 26:ix95-ix95.

Wang H-C, Chan L-P, and Cho S-F. 2019. Targeting the Immune Microenvironment in the Treatment of Head and Neck Squamous Cell Carcinoma. Frontiers in oncology 9.

Warnakulasuriya S. 2009. Global epidemiology of oral and oropharyngeal cancer. Oral oncology 45:309-316.

Peer) reviewing PDF | (2020:01:45342:2:1:NEW 12 Aug 2020) 
492

493

Peer] reviewing PDF | (2020:01:45342:2:1:NEW 12 Aug 2020) 


\section{Table $\mathbf{1}$ (on next page)}

Table 1. Baseline characteristics in the entire cohort $(\mathrm{N}=106)$.

HPC: hypopharyngeal cancer; OC: oral cavity cancer; OPC: oropharyngeal cancer; LVI: lymphovascular invasion; PNI: perineural invasion; ENE: extranodal extension. 
1

\begin{tabular}{|c|c|}
\hline Variables & $\mathrm{n}(\%)$ \\
\hline Age, years $($ mean $\pm \mathrm{SD})$ & $55.1 \pm 9.9$ \\
\hline Alcohol & $71(67.0 \%)$ \\
\hline Betel nuts & $76(71.7 \%)$ \\
\hline Smoking & $79(74.5 \%)$ \\
\hline \multicolumn{2}{|l|}{ Primary sites } \\
\hline HPC & $21(19.8 \%)$ \\
\hline $\mathrm{OC}$ & $68(64.1 \%)$ \\
\hline OPC & $17(16.0 \%)$ \\
\hline \multicolumn{2}{|l|}{ Grade } \\
\hline 1 & $28(26.4 \%)$ \\
\hline 2 & $57(53.8 \%)$ \\
\hline 3 & $16(15.1 \%)$ \\
\hline Unknown & $5(4.7 \%)$ \\
\hline Margin positivity & $11(10.4 \%)$ \\
\hline LVI, positive & $4(3.8 \%)$ \\
\hline PNI, positive & $9(8.5 \%)$ \\
\hline ENE, positive & $5(4.7 \%)$ \\
\hline \multicolumn{2}{|l|}{ Tumor size } \\
\hline T0 & $2(1.9 \%)$ \\
\hline $\mathrm{T} 1$ & $14(13.2 \%)$ \\
\hline $\mathrm{T} 2$ & $24(22.6 \%)$ \\
\hline $\mathrm{T} 3$ & $16(15.1 \%)$ \\
\hline $\mathrm{T} 4$ & $50(47.2 \%)$ \\
\hline \multicolumn{2}{|l|}{ Lymph node status } \\
\hline N0 & $27(25.5 \%)$ \\
\hline N1 & $12(11.3 \%)$ \\
\hline $\mathrm{N} 2$ & $56(52.8 \%)$ \\
\hline N3 & $11(10.4 \%)$ \\
\hline \multicolumn{2}{|l|}{ Stage at initial diagnosis } \\
\hline I & $9(8.5 \%)$ \\
\hline II & $6(5.7 \%)$ \\
\hline III & $11(10.4 \%)$ \\
\hline IV & $80(75.5 \%)$ \\
\hline
\end{tabular}

2 Table 1. Baseline characteristics in the entire cohort $(\mathrm{N}=106)$. 
3 HPC: hypopharyngeal cancer; OC: oral cavity cancer; OPC: oropharyngeal cancer; LVI:

4 lymphovascular invasion; PNI: perineural invasion; ENE: extranodal extension. 


\section{Table 2 (on next page)}

Table 2. Treatment modality.

CRT: concurrent chemoradiotherapy; PF: cisplatin and fluorouracil; ORR: overall response rate; DCR: disease control rate; PFS: progression-free survival; OS: overall survival; $95 \% \mathrm{Cl}$ : $95 \%$ confidence intervals. 
1

\begin{tabular}{ll}
\hline Variables & $\mathrm{n}(\%)$ \\
\hline
\end{tabular}

Previous treatment

Surgery $\quad 83(78.3 \%)$

Chemotherapy $\quad 86(81.1 \%)$

CRT $85(80.2 \%)$

CRT-refractory $34(32.1 \%)$

Cetuximab applied reason

Metastasis $\quad 65(61.3 \%)$

Recurrence $41(38.7 \%)$

Cetuximab cycle, median (range) $11(2-24)$

$<11 \quad 46(43.4 \%)$

$\geq 11 \quad 60(56.6 \%)$

Regimen of chemotherapy

$\mathrm{PF}$

$76(71.7 \%)$

Taxane-based $17(16.0 \%)$

Others $13(12.3 \%)$

Platinum

Cisplatin

$85(80.2 \%)$

Carboplatin $\quad 5(4.7 \%)$

Chemotherapy dose

$60 / 800$

$36(34.0 \%)$

$75 / 1000$

$57(53.8 \%)$

Disease progressed

$105(99.1 \%)$

ORR

$30(28.3 \%)$

DCR

$51(48.1 \%)$

Median PFS (months, 95\% CI)

$5.00(3.00-6.00)$

All-cause mortality

$68(64.2 \%)$

Median OS (months, 95\% CI)

$9.23(7.03-13.84)$

2 Table 2. Treatment modality.

3 CRT: concurrent chemoradiotherapy; PF: cisplatin and fluorouracil; ORR: overall response rate;

4 DCR: disease control rate; PFS: progression-free survival; OS: overall survival; 95\% CI: 95\%

5 confidence intervals. 


\section{Table 3 (on next page)}

Table 3. Cox regression for disease progression.

HPC: hypopharyngeal cancer; OC: oral cavity cancer; OPC: oropharyngeal cancer; LVI: lymphovascular invasion; PNI: perineural invasion; ENE: extranodal extension; CRT: concurrent chemoradiotherapy; PF: cisplatin and fluorouracil; HR: hazard ratio; 95\% Cl: 95\% confidence intervals. *Variables with p-value less than 0.2 in univariate analysis were included in multivariable model. 


\begin{tabular}{|c|c|c|c|c|c|}
\hline \multirow{2}{*}{ Variables } & \multirow{2}{*}{ Comparison } & \multicolumn{2}{|c|}{ Univariate } & \multicolumn{2}{|c|}{ Multivariable* } \\
\hline & & $\mathrm{HR}(95 \% \mathrm{CI})$ & $P$ & $\mathrm{HR}(95 \% \mathrm{CI})$ & $P$ \\
\hline Age & Years & $0.99(0.97-1.01)$ & 0.502 & - & \\
\hline Alcohol & Yes vs. no & $1.47(0.88-2.44)$ & 0.141 & $1.47(0.81-2.64)$ & 0.202 \\
\hline Betel nuts & Yes vs. no & $1.17(0.67-2.05)$ & 0.578 & - & \\
\hline Smoking & Yes vs. no & $0.92(0.50-1.69)$ & 0.783 & - & \\
\hline \multirow[t]{2}{*}{ Histology } & OC vs. HPC & $1.32(0.81-2.17)$ & 0.270 & - & \\
\hline & OPC vs. HPC & $0.95(0.49-1.83)$ & 0.871 & - & \\
\hline Margin & With vs. without residual tumor & $1.30(0.67-2.51)$ & 0.442 & - & \\
\hline \multirow[t]{2}{*}{ Grade } & 2 vs. 1 & $0.87(0.55-1.38)$ & 0.563 & - & \\
\hline & 3 vs. 1 & $1.03(0.56-1.91)$ & 0.920 & - & \\
\hline LVI & Positive vs. negative & $2.04(0.69-6.02)$ & 0.195 & $0.43(0.11-1.72)$ & 0.231 \\
\hline PNI & Positive vs. negative & $2.89(1.26-6.65)$ & 0.012 & $3.19(1.08-9.46)$ & 0.036 \\
\hline ENE & Positive vs. negative & $1.18(0.38-3.61)$ & 0.776 & - & \\
\hline \multirow[t]{4}{*}{ Tumor size } & T1 vs. T0 & $0.19(0.04-0.85)$ & 0.029 & $0.75(0.14-3.96)$ & 0.739 \\
\hline & $\mathrm{T} 2$ vs. T0 & $0.29(0.07-1.28)$ & 0.102 & $0.78(0.16-3.75)$ & 0.751 \\
\hline & T3 vs. T0 & $0.41(0.09-1.83)$ & 0.244 & - & \\
\hline & T4 vs. T0 & $0.27(0.06-1.13)$ & 0.073 & $0.82(0.17-3.89)$ & 0.805 \\
\hline \multirow[t]{3}{*}{ Lymph node status } & N1 vs. N0 & $1.19(0.60-2.37)$ & 0.620 & - & \\
\hline & N2 vs. N0 & $1.73(1.06-2.81)$ & 0.027 & $1.85(0.98-3.51)$ & 0.059 \\
\hline & N3 vs. N0 & $2.04(0.98-4.24)$ & 0.055 & $2.57(1.03-6.43)$ & 0.043 \\
\hline \multirow[t]{3}{*}{ Stage } & II vs. I & $1.66(0.59-4.69)$ & 0.339 & - & \\
\hline & III vs. I & $1.76(0.72-4.28)$ & 0.214 & - & \\
\hline & IV vs. I & $1.50(0.75-3.02)$ & 0.252 & - & \\
\hline Surgery & With vs. without & $0.80(0.50-1.28)$ & 0.354 & - & \\
\hline Chemotherapy before target therapy & With vs. without & $0.87(0.53-1.42)$ & 0.585 & - & \\
\hline CRT-refractory & Yes vs. no & $1.32(0.87-1.99)$ & 0.191 & $1.18(0.72-1.91)$ & 0.511 \\
\hline Cetuximab applied reason & Metastasis vs. recurrence & $1.002(0.68-1.49)$ & 0.992 & - & \\
\hline Cetuximab cycle, median (range) & $\geq 11$ vs. $<11$ & $0.19(0.11-0.30)$ & $<0.001$ & $0.18(0.09-0.33)$ & $<0.001$ \\
\hline \multirow[t]{2}{*}{ Regimen of chemotherapy } & Taxane-based vs. PF & $0.75(0.44-1.29)$ & 0.297 & - & \\
\hline & Others vs. PF & $0.85(0.47-1.54)$ & 0.591 & - & \\
\hline Platinum & Carboplatin vs. Cisplatin & $0.55(0.22-1.39)$ & 0.206 & - & \\
\hline
\end{tabular}


Chemotherapy dose $75 / 1000$ vs. $60 / 800$

$0.90(0.56-1.43)$

0.644

2 Table 3. Cox regression for disease progression. HPC: hypopharyngeal cancer; OC: oral cavity cancer; OPC: oropharyngeal cancer;

3 LVI: lymphovascular invasion; PNI: perineural invasion; ENE: extranodal extension; CRT: concurrent chemoradiotherapy; PF:

4 cisplatin and fluorouracil; HR: hazard ratio; 95\% CI: 95\% confidence intervals.

5 *Variables with p-value less than 0.2 in univariate analysis were included in multivariable model. 


\section{Table 4 (on next page)}

Table 4. Cox regression for overall mortality.

HPC: hypopharyngeal cancer; OC: oral cavity cancer; OPC: oropharyngeal cancer; LVI: lymphovascular invasion; PNI: perineural invasion; ENE: extranodal extension; CRT: concurrent chemoradiotherapy; PF: cisplatin and fluorouracil; HR: hazard ratio; 95\% Cl: 95\% confidence intervals. *Variables with p-value less than 0.2 in univariate analysis were included in multivariable model. 


\begin{tabular}{|c|c|c|c|c|c|}
\hline \multirow{2}{*}{ Variables } & \multirow{2}{*}{ Comparison } & \multicolumn{2}{|c|}{ Univariate } & \multicolumn{2}{|c|}{ Multivariable* } \\
\hline & & $\mathrm{HR}(95 \% \mathrm{CI})$ & $P$ & $\operatorname{HR}(95 \% \mathrm{CI})$ & $P$ \\
\hline Age & Years & $1.004(0.98-1.03)$ & 0.738 & - & \\
\hline Alcohol & Yes vs. no & $1.87(0.95-3.67)$ & 0.070 & $2.00(0.94-4.26)$ & 0.073 \\
\hline Betel nuts & Yes vs. no & $1.50(0.74-3.04)$ & 0.260 & - & \\
\hline Smoking & Yes vs. no & $0.72(0.37-1.42)$ & 0.341 & - & \\
\hline \multirow{2}{*}{ Histology } & OC vs. HPC & $1.41(0.76-2.64)$ & 0.278 & - & \\
\hline & OPC vs. HPC & $1.44(0.67-3.12)$ & 0.350 & - & \\
\hline Margin & With vs. without residual tumor & $0.86(0.40-1.86)$ & 0.703 & - & \\
\hline \multirow[t]{2}{*}{ Grade } & 2 vs. 1 & $0.91(0.52-1.60)$ & 0.737 & - & \\
\hline & 3 vs. 1 & $1.16(0.57-2.36)$ & 0.672 & - & \\
\hline LVI & Positive vs. negative & $1.89(0.62-5.78)$ & 0.266 & - & \\
\hline PNI & Positive vs. negative & $1.92(0.76-4.88)$ & 0.169 & $0.54(0.16-1.80)$ & 0.318 \\
\hline ENE & Positive vs. negative & $0.92(0.27-3.14)$ & 0.890 & - & \\
\hline \multirow[t]{4}{*}{ Tumor size } & T1 vs. T0 & $0.05(0.01-0.27)$ & $<0.001$ & $0.10(0.01-1.13)$ & 0.063 \\
\hline & T2 vs. T0 & $0.07(0.02-0.36)$ & 0.001 & $0.14(0.02-1.02)$ & 0.052 \\
\hline & T3 vs. T0 & $0.06(0.01-0.33)$ & 0.001 & $0.21(0.02-1.73)$ & 0.145 \\
\hline & T4 vs. T0 & $0.08(0.02-0.35)$ & 0.001 & $0.26(0.03-2.01)$ & 0.198 \\
\hline \multirow[t]{3}{*}{ Lymph node status } & N1 vs. N0 & $1.59(0.63-4.00)$ & 0.322 & $3.09(0.72-13.16)$ & 0.128 \\
\hline & N2 vs. N0 & $2.09(1.11-3.92)$ & 0.022 & $4.79(1.55-14.77)$ & 0.006 \\
\hline & N3 vs. N0 & $1.92(0.76-4.88)$ & 0.170 & $7.34(1.85-29.16)$ & 0.005 \\
\hline \multirow[t]{3}{*}{ Stage } & II vs. I & $2.75(0.79-9.51)$ & 0.110 & $1.69(0.19-15.31)$ & 0.640 \\
\hline & III vs. I & $0.85(0.23-3.18)$ & 0.812 & $0.15(0.02-1.42)$ & 0.098 \\
\hline & IV vs. I & $1.56(0.62-3.91)$ & 0.341 & $0.14(0.02-1.08)$ & 0.060 \\
\hline Surgery & With vs. without & $0.66(0.38-1.13)$ & 0.127 & $0.83(0.46-1.51)$ & 0.541 \\
\hline Chemotherapy before target therapy & With vs. without & $1.25(0.64-2.46)$ & 0.517 & - & \\
\hline CRT-refractory & Yes vs. no & $1.20(0.73-1.98)$ & 0.479 & - & \\
\hline Cetuximab applied reason & Metastasis vs. recurrence & $1.16(0.70-1.91)$ & 0.561 & - & \\
\hline Cetuximab cycle, median (range) & $\geq 11$ vs. $<11$ & $0.46(0.28-0.75)$ & 0.002 & $0.48(0.27-0.84)$ & 0.010 \\
\hline \multirow[t]{2}{*}{ Regimen of chemotherapy } & Taxane-based vs. PF & $0.75(0.38-1.49)$ & 0.417 & - & \\
\hline & Others vs. PF & $0.90(0.43-1.89)$ & 0.777 & - & \\
\hline Platinum & Carboplatin vs. Cisplatin & $0.51(0.16-1.64)$ & 0.260 & - & \\
\hline
\end{tabular}


Chemotherapy dose

$75 / 1000$ vs. $60 / 800$

$1.19(0.66-2.17)$

0.564

2 Table 4. Cox regression for overall mortality. HPC: hypopharyngeal cancer; OC: oral cavity cancer; OPC: oropharyngeal cancer; LVI:

3 lymphovascular invasion; PNI: perineural invasion; ENE: extranodal extension; CRT: concurrent chemoradiotherapy; PF: cisplatin

4 and fluorouracil; HR: hazard ratio; 95\% CI: 95\% confidence intervals.

5 *Variables with p-value less than 0.2 in univariate analysis were included in multivariable model. 


\section{Table 5 (on next page)}

Table 5. Adverse effects observed according to CTCAE version 4.0. 
1 Table 5. adverse effects observed according to CTCAE version 4.0.

\begin{tabular}{|c|c|c|c|c|c|c|c|c|c|c|c|c|}
\hline & \multicolumn{4}{|c|}{$\mathrm{PF}$} & \multicolumn{4}{|c|}{ Taxane-based } & \multicolumn{4}{|c|}{ Others } \\
\hline & \multicolumn{2}{|c|}{ All grades } & \multicolumn{2}{|c|}{ Grade 3-4 } & \multicolumn{2}{|c|}{ All grades } & \multicolumn{2}{|c|}{ Grade 3-4 } & \multicolumn{2}{|c|}{ All grades } & \multicolumn{2}{|c|}{ Grade 3-4 } \\
\hline & No. & $\%$ & No. & $\%$ & No. & $\%$ & No. & $\%$ & No. & $\%$ & No. & $\%$ \\
\hline Febrile & 7 & 9.2 & 1 & 1.3 & 4 & 23.5 & 1 & 5.9 & 2 & 15.4 & 0 & - \\
\hline Neutropenia & 24 & 31.6 & 1 & 1.3 & 6 & 35.3 & 0 & - & 2 & 15.4 & 0 & - \\
\hline Skin rash & 46 & 60.5 & 2 & 2.6 & 9 & 52.9 & 0 & - & 5 & 38.5 & 0 & - \\
\hline Anemia & 51 & 67.1 & 2 & 2.6 & 14 & 82.4 & 0 & - & 4 & 30.8 & 0 & - \\
\hline $\begin{array}{l}\text { Hypomagnesemi } \\
\text { a }\end{array}$ & 31 & 40.8 & 0 & - & 11 & 64.7 & 0 & - & 4 & 30.8 & 0 & - \\
\hline Pneumonia & 7 & 9.2 & 0 & - & 2 & 11.8 & 0 & - & 1 & 7.7 & 0 & - \\
\hline Infusion reaction & 5 & 6.6 & 0 & - & 0 & - & 0 & - & 0 & - & 0 & - \\
\hline Vomiting & 28 & 36.8 & 1 & 1.3 & 5 & 29.4 & 0 & - & 8 & 61.5 & 0 & - \\
\hline
\end{tabular}

2 


\section{Table 6(on next page)}

Table 6. Comparisons between different trials of cetuximab-based chemotherapy.

ORR: overall response rate; OS: overall survival; Q3W: every three weeks; AUC: area under the curve. 


\begin{tabular}{|c|c|c|c|c|c|c|c|c|}
\hline Study & Country & Year & Author & Chemotherapy & $\begin{array}{l}\text { Cetuximab } \\
\text { maintenance }\end{array}$ & Numbers & $\begin{array}{l}\text { ORR } \\
(\%)\end{array}$ & $\begin{array}{l}\text { OS } \\
(\mathbf{m})\end{array}$ \\
\hline Extreme & Belgium & 2008 & $\begin{array}{l}\text { Vermorken } \\
\text { JB }\end{array}$ & $\begin{array}{l}\text { Cisplatin } 100 \mathrm{mg} / \mathrm{m} 2 \mathrm{D} 1 \\
\text { Fluorouracil 1000mg/m2 D1-4 Q3W }\end{array}$ & Weekly & 222 & 36 & 10.1 \\
\hline $\begin{array}{l}\text { GORTEC } \\
2008-03\end{array}$ & $\begin{array}{l}\text { France and } \\
\text { Belgium }\end{array}$ & 2012 & Guigay J & $\begin{array}{l}\text { Cisplatin } 75 \text { mg/m2 D1 } \\
\text { Docetaxel 75mg/m2 D1 Q3W }\end{array}$ & Biweekly & 54 & 44 & 14 \\
\hline NCT01177956 & $\begin{array}{l}\text { China and } \\
\text { South } \\
\text { Korea }\end{array}$ & 2014 & Guo Y & $\begin{array}{l}\text { Cisplatin } 75 \mathrm{mg} / \mathrm{m} 2 \mathrm{D} 1 \\
\text { Fluorouracil 750mg/m2 D1-5 Q3W }\end{array}$ & Weekly & 68 & 55.9 & 12.6 \\
\hline CET-INT & Italy & 2017 & Bossi P & $\begin{array}{l}\text { Cisplatin } 75 \mathrm{mg} / \mathrm{m} 2 \mathrm{D} 1 \\
\text { Paclitaxel } 175 \mathrm{mg} / \mathrm{m} 2 \mathrm{D} 1 \mathrm{Q} 3 \mathrm{~W}\end{array}$ & Weekly & 191 & 51.7 & 11 \\
\hline $\begin{array}{l}\text { CSPRO- } \\
\text { HN02 }\end{array}$ & Japan & 2016 & Tahara M & $\begin{array}{l}\text { Carboplatin AUC 2.5 D1, D8 } \\
\text { Paclitaxel } 100 \mathrm{mg} / \mathrm{m} 2 \mathrm{D} 1, \mathrm{D} 8 \mathrm{Q} 3 \mathrm{~W}\end{array}$ & Weekly & 47 & 40 & 14.7 \\
\hline CACTUX & USA & 2018 & Adkins D & $\begin{array}{l}n a b \text {-paclitaxel } 100 \mathrm{mg} / \mathrm{m} 2 \text { weekly } \\
\text { Carboplatin AUC } 5 \text { D1 or Cisplatin } 75 \mathrm{mg} / \mathrm{m} 2 \mathrm{D} 1 \mathrm{Q} 3 \mathrm{~W}\end{array}$ & Weekly & 32 & 63 & 18.8 \\
\hline CETMET & Demark & 2018 & Friesland S & $\begin{array}{l}\text { Cisplatin } 75 \text { mg/m2 D1 } \\
\text { Paclitaxel } 175 \text { mg/m2 D1 Q3W }\end{array}$ & Biweekly & 85 & 63 & 10.2 \\
\hline TPEX & $\begin{array}{l}\text { France and } \\
\text { Belgium }\end{array}$ & 2019 & Guigay J & $\begin{array}{l}\text { Cisplatin } 75 \mathrm{mg} / \mathrm{m} 2 \mathrm{D} 1 \\
\text { Docetaxel } 75 \mathrm{mg} / \mathrm{m} 2 \mathrm{D} 1 \mathrm{Q} 3 \mathrm{~W}\end{array}$ & Biweekly & 269 & 46 & 14.5 \\
\hline
\end{tabular}




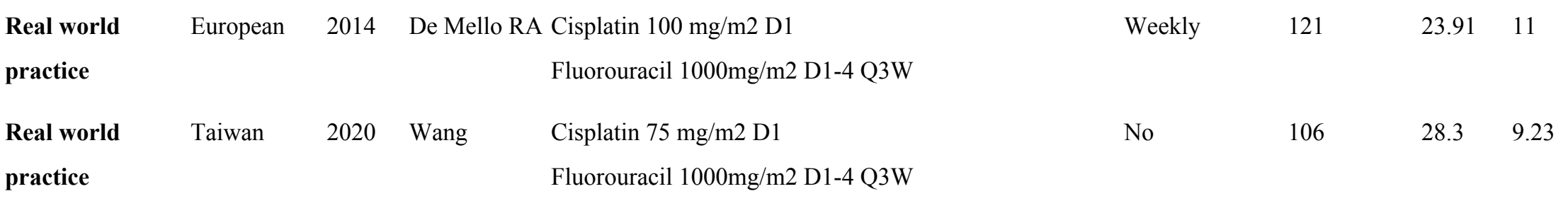

2 Table 6. Comparisons between different trials of cetuximab-based chemotherapy. ORR: overall response rate; OS: overall survival; 3 Q3W: every three weeks; AUC: area under the curve. 
Figure 1

Figure 1. Treatment Schema.

Tx: treatment; PF: cisplatin and fluorouracil; CT: computed tomography; MRI: magnetic resonance imaging; SD: stable disease; PR: partial response.

\section{Recurrent/metastatic HNSCC}

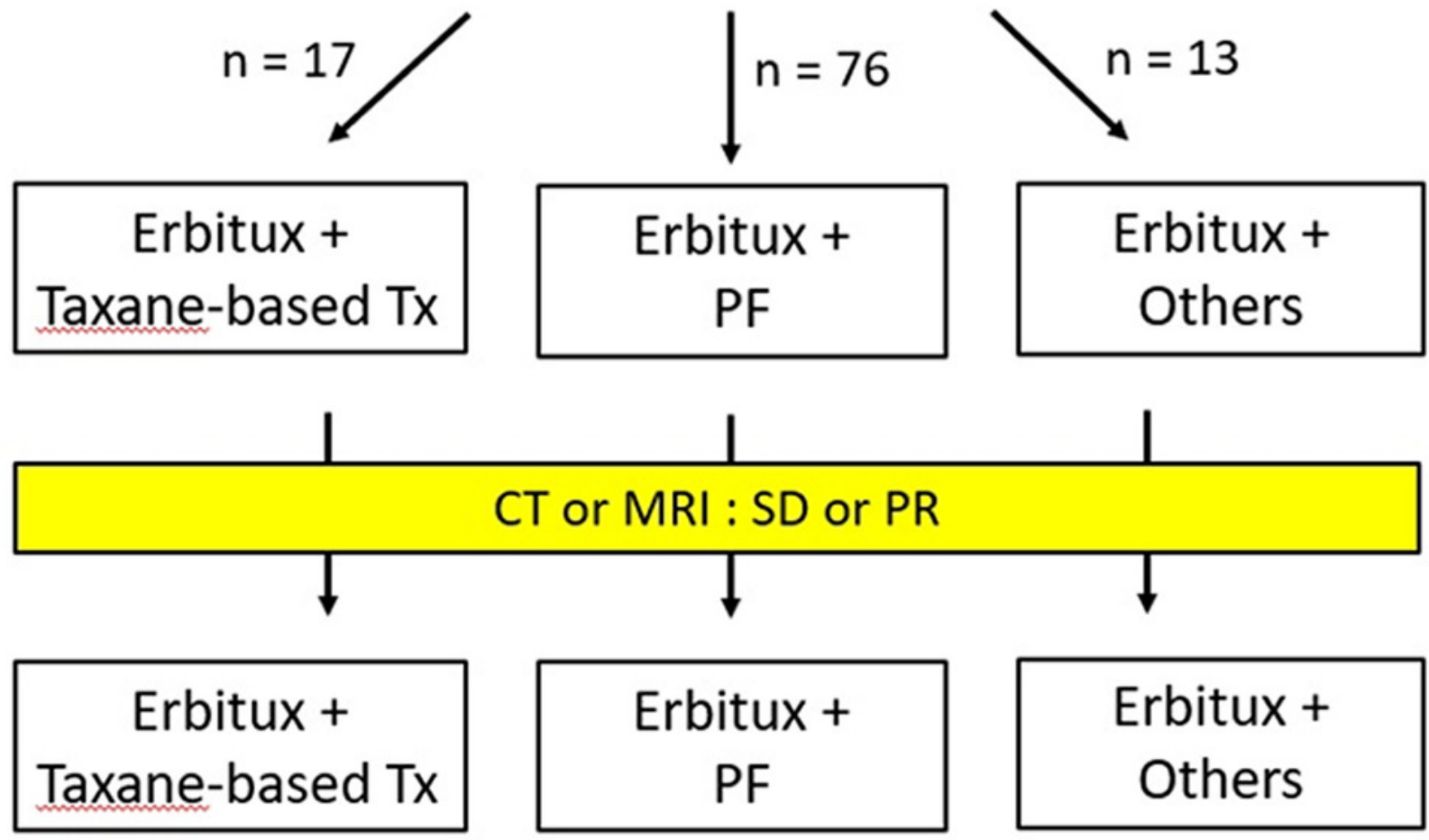


Figure 2

Figure 2. Progression-free survival curve.

Progression-free survival curve according to (A) cetuximab cycle, (B) previous CRT, (C) different chemotherapy regimens, (D) different doses of PF, and (E) CRT-refractory patents or not. 


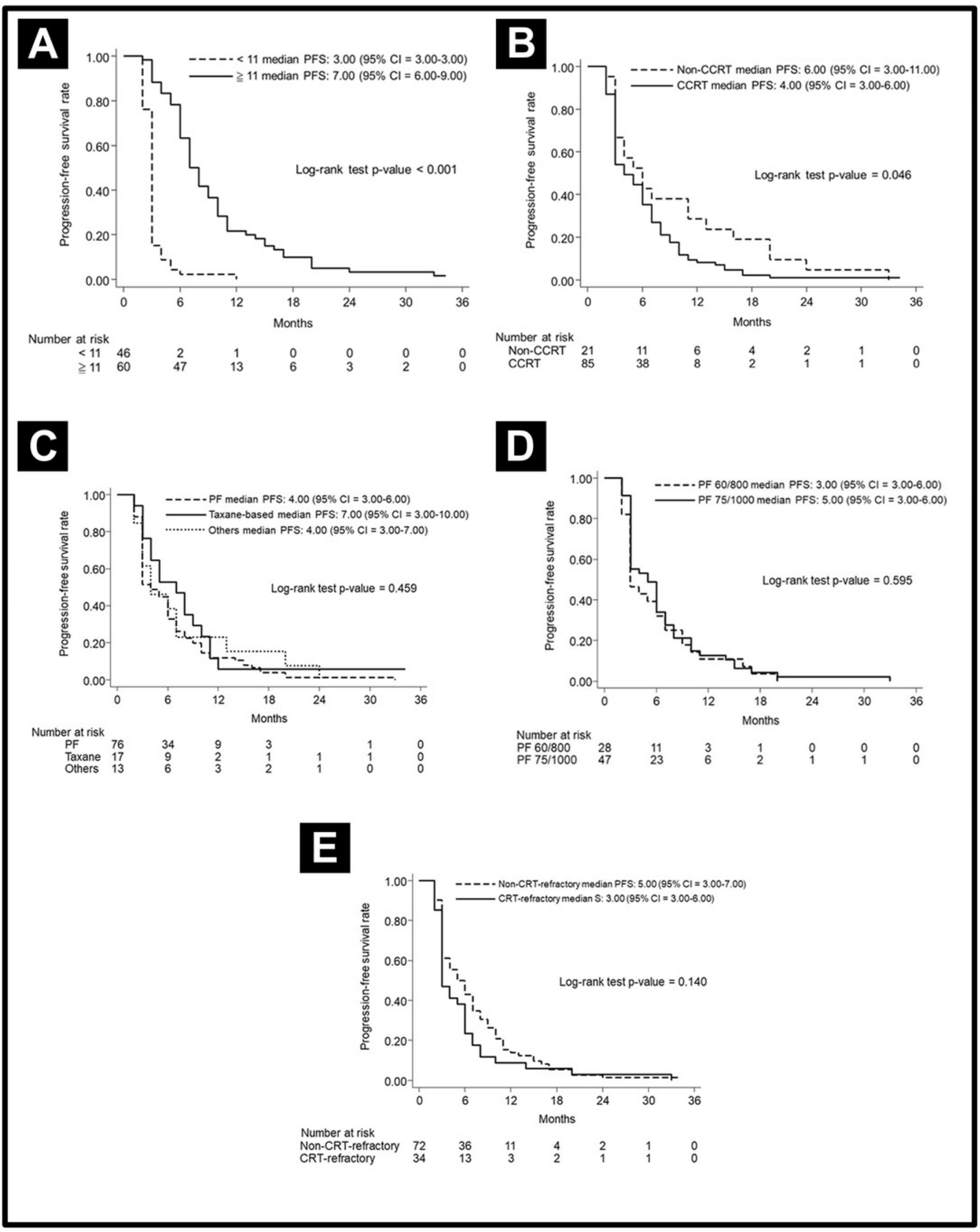


Figure 3

Figure 3. Overall survival curve.

Overall survival curve according to (A) cetuximab cycle,.(B) different chemotherapy regimens, and (C) different doses of PF.

A

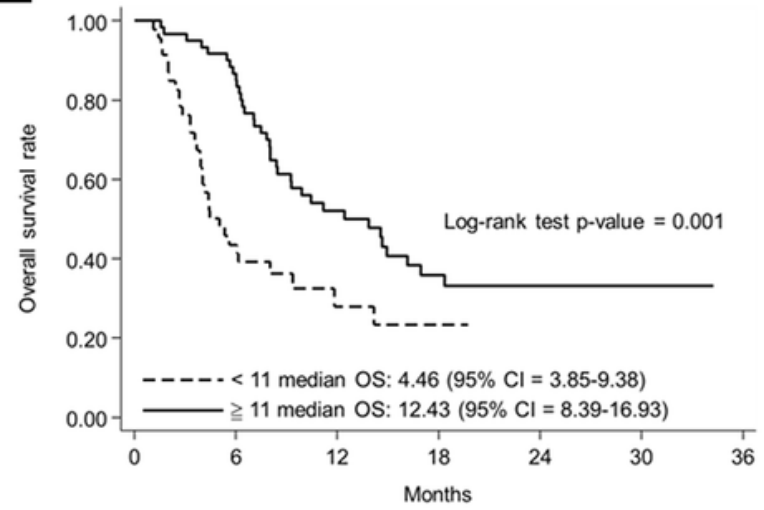

Number at risk

$\begin{array}{llllclll}<11 & 46 & 20 & 6 & 3 & 0 & 0 & 0 \\ \geqq 11 & 60 & 52 & 26 & 14 & 7 & 2 & 0\end{array}$

B

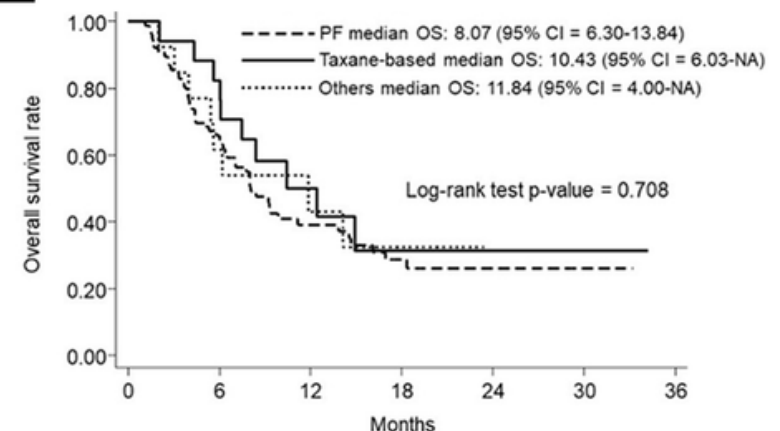
$\begin{array}{lccccccc}\text { Number at risk } & & & & & & \\ \text { PF } & 76 & 50 & 22 & 12 & 5 & & 0 \\ \text { Taxane-based } & 17 & 14 & 6 & 3 & 2 & 1 & 0 \\ \text { Others } & 13 & 8 & 4 & 2 & 0 & 0 & 0\end{array}$

\section{C}
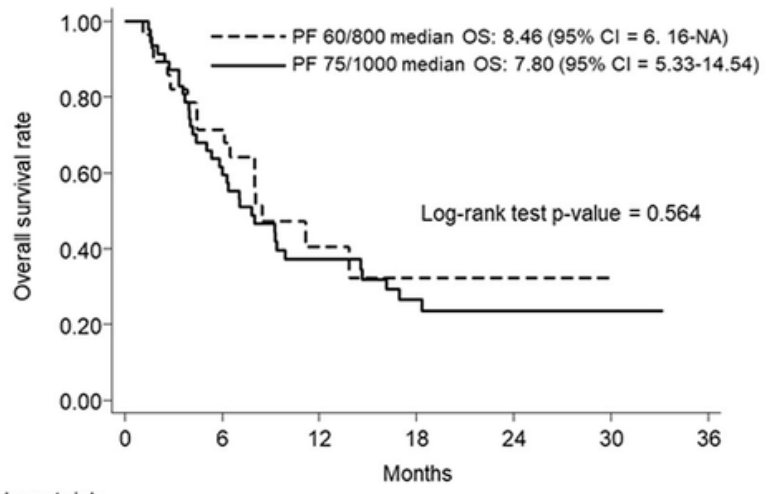

Number at risk

$\begin{array}{ccccc}6 & 3 & 1 & 0 & 0 \\ 16 & 9 & 4 & 1 & 0\end{array}$


Figure 4

Figure 4. Subgroups analysis in CRT-refractory patients.

(A)Progression-free survival curve and (B) Overall curve according to the cetuximab cycle in CRT- refractory patients.

\section{A}

$1.00-1$ i $-\cdots<11$ median PFS: $3.00(95 \% \mathrm{Cl}=3.00-3.00)$

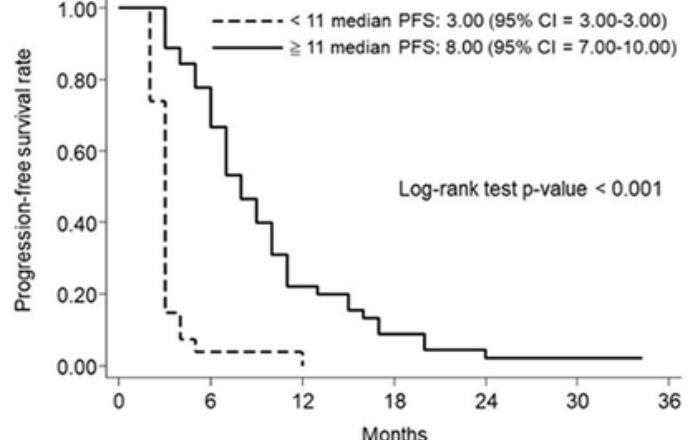

Number at risk

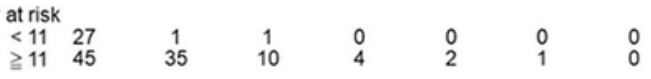

B

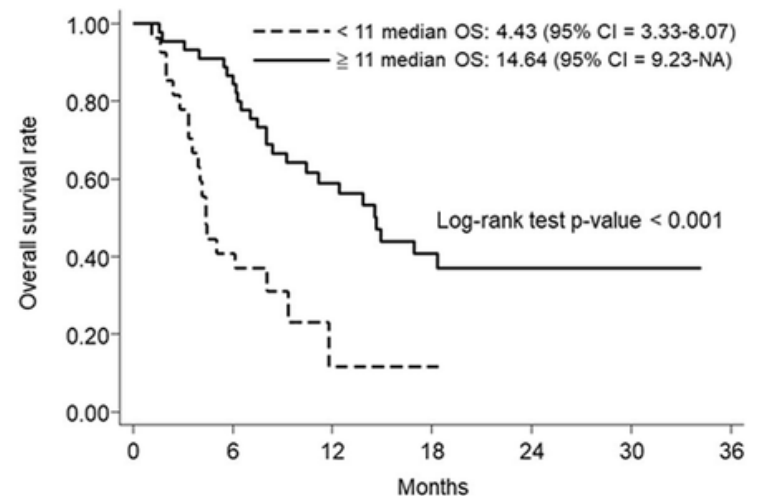

Number at risk

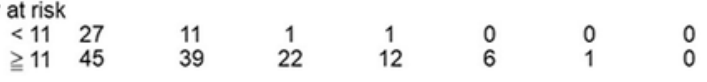

